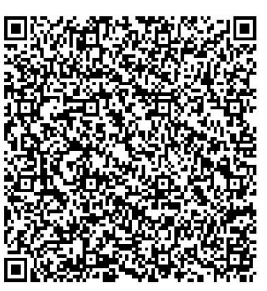

\title{
ECOTOURISM AND SUSTAINABILITY: AN ANALYSIS OF STRATEGIES, PRACTICES AND PROBLEMS
}

\author{
Sheker Naik* \& K. Puttanna**
}

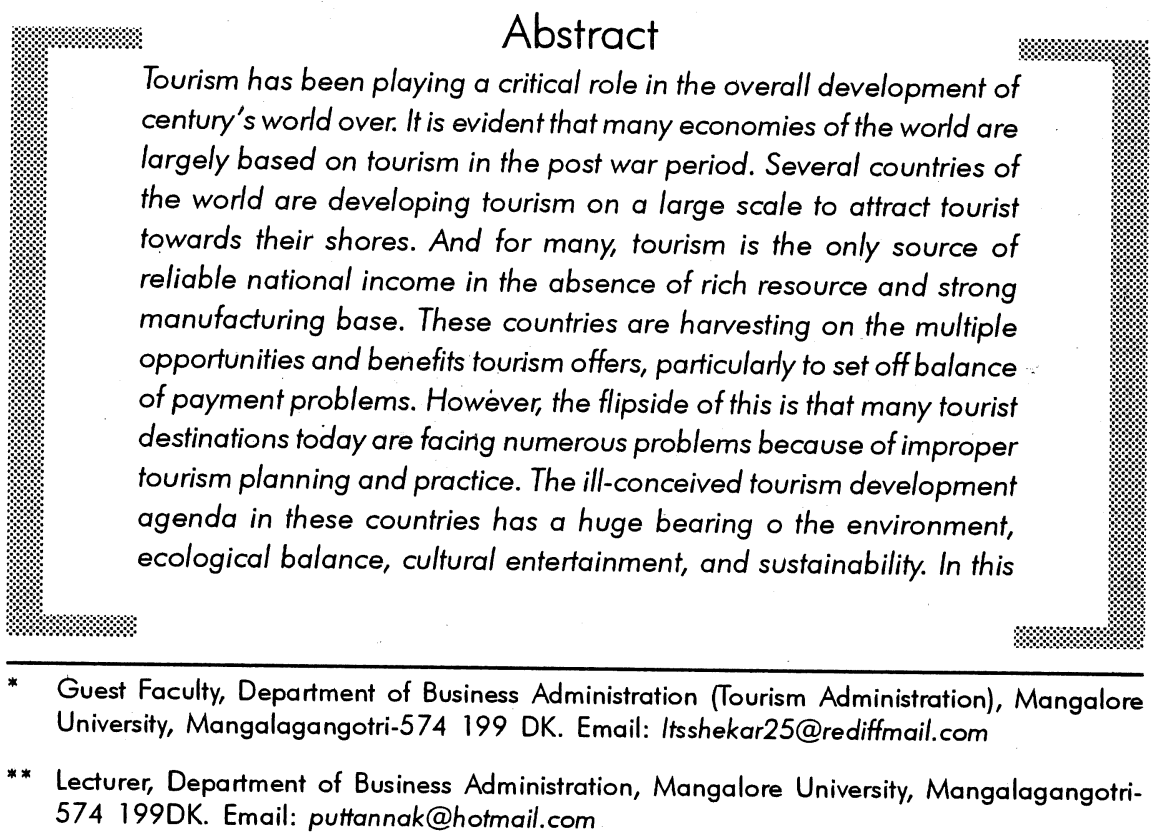




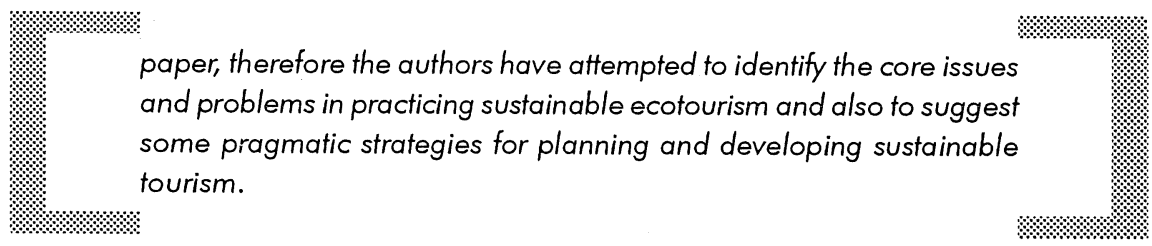

\section{Introduction}

Tourism is one of the fastest growing endeavors as well as the major source of foreign exchange earning and employment for many developed and developing countries. Alongside, we find it to be the most debated endeavor as there has been an increasing focus on tourism's impact on the sustainability of natural and cultural environments. Therefore, some are seriously arguing that tourism today has become a double-edged activity. It has the potential to contribute in a positive manner to socio- economic achievements of a country and, at the same time, its fast and sometimes uninhibited growth can be the chief cause of degradation of the environment and loss of local identity and traditional cultures. Biological, physical, and cultural resources are in fact the assets that attract tourist. However, the stress imposed by tourism activities on delicate biological, physical and cultural systems of a given country accelerates and aggravates their attenuation. Paradoxically, the very success of tourism may lead to the degradation of the natural and physiocultural environments by draining natural quintessence, which in turn reduces the site attractiveness to tourists, the very commodity that tourism has to offer. Therefore, the critic's argument for sustainable development of tourism becomes highly imperative.

The main thrust of the concept of sustainable tourism is that it can make positive improvements to biological and cultural diversity and its conservation, particularly when local communities are directly involved with all the participants in tourism activities. If such local communities are actively engaged in tourist activities, they receive income from them. This enhances their awareness on and understanding of the true value of the natural and cultural resources around them. This would, in turn, prompt the local communities to resort voluntarily to greater protection and conservation of those resources as they are recognized to be the source of income.

Moreover, sustainable tourism can serve as a major educational opportunity, increasing knowledge of and respect for natural ecosystems, biological and cultural resources. Other benefits include the provision of incentives for maintaining traditional arts and crafts, traditional knowledge, and innovations and practices that contribute to the sustainable use of biological diversity. Therefore, in considering the role of tourism in the sustainable use of biological resources and their diversity, it is important that the potential adverse impacts of tourism are fully considered. Consequently, sustainable tourism should become 
everybody's interest. Given that a high percentage of tourism involves visits to naturally and culturally distinguished sites, generating large amounts of revenue, there are clearly major opportunities for investing in the maintenance and sustainable use of these tourist resources. Along with the efforts to maximize benefits, efforts must also be made to minimize the adverse impacts of the tourism industry on biological diversity.

\section{What is Sustainable development?}

To understand the principles behind sustainable tourism development, it is first necessary to appreciate how the idea evolved. During the $1980 \mathrm{~s}$ it became apparent that major global environmental changes were occurring suddenly and silently and that scientists had not predicted these changes. The world also became aware that there was an element of uncertainty and risk in relation to the effect of the range of human activities on global environment. The concept of sustainable development came from this realization. It was first mentioned in 1987 in a report published by World Commission on Environment and Development. WTO propounds those sustainable tourism developments meet the needs of present tourists and the host regions while protecting and enhancing opportunities for the future. It is envisaged as leading to management of all resources in such a way that economic, social and aesthetic needs can be fulfilled while maintaining cultural integrity, essential ecological process, biological diversity and life support system.

\section{Sustainable Tourism}

Tourism is most ideally suited to adopt sustainability as guiding philosophy. There are many reasons: Apart from transportation, tourism does not consume additional non-renewal resources. Community's resources, its culture, traditions, shops, leisure facilities etc. represent the core resources base for tourism. Tourism's use of resources, both natural and cultural, should be non-consumptive, making them renewable. Tourism represents one of the few economic opportunities available to remote communities. Tourism provides real opportunities to reduce poverty, to create employment for disadvantage people, and to stimulate regional development. Tourism has proven records to revitalize culture and traditions. Tourism can provide an economic incentive to conserve natural and cultural assets. Tourism has been fostering greater understanding between peoples and a greater global consciousness. But, historically much of tourism has been unsustainable. The main reasons attributed to this are as follows: Tourism is a fierce competitor for resources - the provision of cultural and ecotourism opportunities for tourism may mean that local residents are displaced. The needs of tourists are different than those of local residents and thus, serving tourists may again not suit the needs of local residents. Few 
people understand tourism and the requirements for the development of successful tourism products, meaning that a lot of countries have made unwise investments in tourism. Tourism is often imposed on local communities especially rural and minority at levels and speeds that causes great social disruption.

\section{Problems in Practicing Sustainable Ecotourism}

As theoretical paradigm, sustainable ecotourism offers many advantages, both short term and long-term. However, when it is to be operationalised many problems are encountered. They are:

\section{a) Structural differences}

Tourism activities, as traditionally defined by tourism industry, fundamentally involve transportation and hosting of the tourism consumer in the local community. i.e., "tourist destination", where the tourist product is consumed. No other global industry structures itself in such a way that the consumer is brought to the products, rather than the product being delivered to the consumer in his or her own community. This structural difference produces unique social impacts upon the local tourist community including interruption of local customs and life style, the spread of infectious diseases, changes in local demographics, and changes in local housing and labor markets.

\section{b) Degrading community heritage}

The primary product of tourism is not something produced by the industry. The product is often heritage wealth and expected legacy of the community that serves as the tourist destination. The business activity of the tourism industry is to promote 'marketable' or appealing aspects of the community, transport non-residents into the community, manage the hospitality for and guide the activities of these visitors, provide them with goods and services to purchase during their stay. If these business activities degrade the community's heritage and wealth then the community suffers more directly than the consumer, who can return to his or her own community without responsibility for or awareness of the impacts of his tourist activities.

\section{c) Undermining social relationships and values}

Tourism activities can, in particular, degrade the social and natural wealth of a community. The intrusion of large number of uninformed foreigners into local community system can undermine pre- existing social relationship and values. This is particularly a problem where tourism business is centered in traditional social systems, such as isolated communities or indigenous people. 


\section{d) Environmental Degradation}

Tourism in natural areas, euphemistically called "ecotourism", can be a major source of degradation of local ecological, economic and social system. The intrusion of large number of 'foreigners' with high consumption and high waste into natural areas or into towns with inadequate waste management infrastructure can produce changes to those natural areas at a rate that is far greater than imposed by local residents. These tourism-related changes are lethal when local residents rely on those natural areas for their sustenance. Resulting economic losses can encourage socially harmful economic activities such as prostitution, crime and migrant and child labor.

\section{e) Consumption Stages}

Tourism related consumption has three stages of impacts. First, prior to departure, travel related clothing and equipments, which may be produced under conditions that undermine social and ecological sustainability of the tourist's home communities. Second, when tourists travel to long distance tourist destination, they create considerable atmospheric pollution and other impacts on the global environment. Third, upon arrival at the tourist destination, tourists often continue their accustomed habits of consumption even though these destinations may not have the infrastructure required to manage those consumption patterns.

\section{f) Standardization and alignment of facilities}

Following arrival at tourist destinations, the tourism industry typically strives to host tourists according to standards and amenities of their country of origin. These hospitality standards mimic and encourage high consumption lifestyles of developed countries. The most immediate observable impacts of introducing these high consumption practices into low-consumption communities are:

(a) Degradation of local water and soil quality, with direct impact on local health and economies as a result of lack of adequate water, drainage, waste water and waste management infrastructure to manage the higher volumes of waste produced by higher levels of consumption;

(b) Reduced access by local residents to land, housing and marine resources through, among other things, reallocation of these community resources to foreign tourist residents and inflation of local prices; and

c) Destruction of traditional sources of income. 


\section{The Impact of Tourism}

The following table summarizes a representative cross-section of positive and negative effects that tourism may have upon physical environments, and proposes five key headings under which tourism effects may be grouped. This is in a way the 'Balance sheet' of environmental impacts of tourism on local communities, and calls for introspection and pragmatic strategies to take the edge off them.

\begin{tabular}{|l|l|l|}
\hline Area of effect & Negative impacts & Positive impacts \\
\hline Biodiversity & $\begin{array}{l}\text { Disruption of breeding/ } \\
\text { feeding patterns.Killing } \\
\text { of animals for leisure } \\
\text { (hunting) or to supply } \\
\text { souvenir trade. Loss of } \\
\text { habitats \& change in } \\
\text { species composition. } \\
\text { Destruction of vegetation }\end{array}$ & $\begin{array}{l}\text { Encouragement to } \\
\text { conserve animals as } \\
\text { attractions. Establishment } \\
\text { of protected or } \\
\text { conserved areas to meet } \\
\text { tourism demands. }\end{array}$ \\
\hline $\begin{array}{l}\text { Erosion and physical } \\
\text { damage restoration }\end{array}$ & $\begin{array}{l}\text { Soil erosion damage to } \\
\text { sites through trampling. } \\
\text { Overloading of key } \\
\text { infrastructure (e.g water } \\
\text { supply network) }\end{array}$ & $\begin{array}{l}\text { Tourism revenue to } \\
\text { finance ground repair } \\
\text { and site restoration. }\end{array}$ \\
Improvement of \\
Pollution & $\begin{array}{l}\text { Water pollution through } \\
\text { sewage or fuel spillage } \\
\text { and rubbish from } \\
\text { pleasure boats. } \\
\text { bir pollution (e.g, vehicle } \\
\text { emissions) noise } \\
\text { pollution (e.g from } \\
\text { vehicles or tourist } \\
\text { attractions: bars, discos } \\
\text { etc) and littering }\end{array}$ & $\begin{array}{l}\text { Cleaning programmes to } \\
\text { protect the attractiveness } \\
\text { of the location to tourist. }\end{array}$ \\
\hline
\end{tabular}




\begin{tabular}{|c|c|c|}
\hline Area of effect & Negative impacts & Positive impacts \\
\hline Resource base & $\begin{array}{l}\text { Depletion of ground and } \\
\text { surface water. Diversion } \\
\text { of water supply to meet } \\
\text { tourist needs (e.g golf } \\
\text { courses or pools) } \\
\text { Depletion of local fuel } \\
\text { sources. Depletion of } \\
\text { local building material } \\
\text { sources. }\end{array}$ & $\begin{array}{l}\text { Development of new / } \\
\text { improved sources of } \\
\text { supply. }\end{array}$ \\
\hline $\begin{array}{l}\text { Visual / structural } \\
\text { change }\end{array}$ & $\begin{array}{l}\text { Land transfer to tourism } \\
\text { (from farming) } \\
\text { Detrimental visual impact } \\
\text { on natural and non- } \\
\text { natural landscapes } \\
\text { through tourism } \\
\text { development } \\
\text { Introduction of new } \\
\text { architectural styles. } \\
\text { Changes in (urban) } \\
\text { functions } \\
\text { Physical expansion of } \\
\text { built-up areas. }\end{array}$ & \\
\hline
\end{tabular}

\section{Strategies for Sustainable Development}

Solutions to adverse tourism impacts are to be found in shared interest of local communities, tourism businesses and consumers to maintain natural wealth and social heritage of the tourism destination. To give an expression to this intention, therefore, an institutional mechanism must be first established relative to each destination to articulate and develop this sense of shared interest. To secure the legitimacy of these mechanism the participation of all interested local groups or interests must be guaranteed. The dialogue must take place in an open and transparent way. 
The most direct way to reduce the adverse impacts of tourism-related travel is to increase opportunities for people to engage in appealing tourism activities in their own cities, regions or countries. In various cities of the world, this local tourism concept is known as "green tourism".

Technological solutions to tourism- related pollution in travel and tourism industry are available. To overcome the economic barriers to their implementation, it may be required to have suitable government regulation, obtain development of economic instruments and industry self-regulation.

The solutions to adverse environment impact arising from the local tourist consumption is the establishment of the waste reduction programs and appropriate waste management systems and infrastructure, particularly in developing country. destinations. Again, a choice exists between voluntary and regulatory measures. National governments and tourism businesses, which receive disproportional economic benefits from tourism, share an interest in maintaining tourism-related hard currency inflows and should either directly, provide such infrastructure or ensure that funds are made available to public authorities for this purpose. Without such support, powers should be provided to local authorities to increase local revenues from tourism, through local airport taxes, hotel and service taxes and development fees to finance infrastructure construction and maintenance. Only through such economic instruments can the public cost of tourism activities be internalized in the local tourist economy.

- Tourist businesses can make significant voluntary contribution to resolving the social cost of tourism by;

i. Providing local residents employment and training opportunities including in traditional arts and crafts;

ii. Establishing purchasing guidelines that favor local goods and services procurement;

iii. Making donations and investment in local recreation facilities, parks, cultural facilities and security operations;

and

iv. Establishing local profit sharing arrangements;

- Failing necessary voluntary measures, local government can institute economic incentives and regulatory measures to reward best practices and prevent severe social impacts that need to be resolved at public expense. Ultimately; in the face of private establishments that demonstrate no long-term commitment to 
maintaining the prediction for tourism- which include public safety, environmental quality, infrastructure maintenance, and economic justice- local authorities need to use all power available to protect the cultural and environmental wealth that make an attractive tourist destination.

Partnerships can be established between local governments, airport authorities, regional air quality agencies, airlines, trade unions, NGOs and resident associations to develop an action program to reduce local airport pollution. International travel and tourism organizations and related industry associations could support these partnerships. Measures to reduce high altitude pollution by aircrafts require similar initiative by industry and by the Government at national level and international levels.

- The creation of mechanisms to inform and involve tourism consumers in making educated choices about their activities as tourists in distant tourist destinations. These efforts would ensure that tourism consumers, as with industry begin to recognize and understand tourist destinations as living communities that deserve their support and respect. Communications from tourism consumers to tourism industry and to local authorities on their desire to reduce the adverse impacts of their tourism activities can be essential to mobilizing changes in industry and government practices. International consumer advocacy organizations and trade unions can play an important role in forming consumers about tourism development activities that violate basic principles of sustainable development. Provision of such information to LGOs can facilitate local authority responsiveness to identified problems.

\section{The Ecotourism Paradigm}

\section{Integrated Sustainable Resource Use}

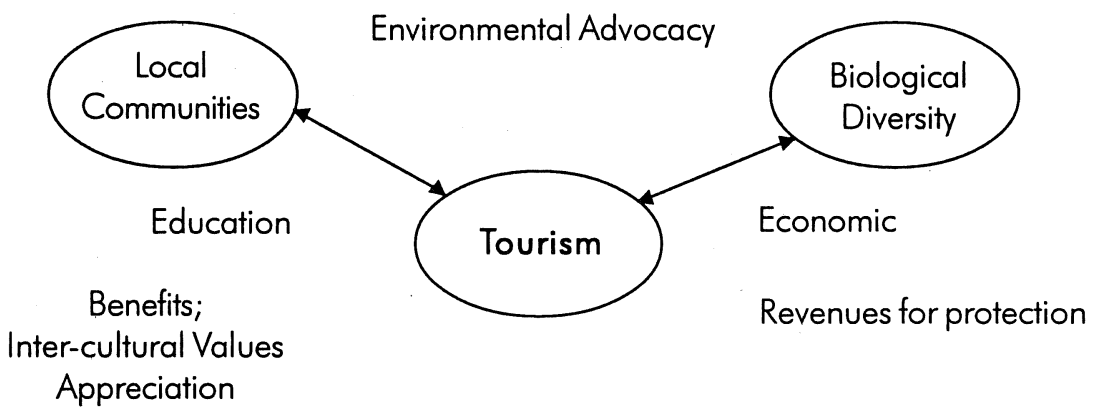


All the three elements in this model are in co-interaction. Local communities use the natural resources, but they also protect them. Tourists come to enjoy the nature and get knowledge about it, but they also can pollute and destroy it, or on the other side help to protect it by drawing attention to unique natural resources in the area. Local communities affect tourists by giving them knowledge of their culture and way of life. Tourist impact on the local populations can be first of all economic by generating income, developing resources, sharing knowledge and experience etc. whenever we develop new tourist destination we should always bear in mind this co-interaction.

In order to decrease negative effects on local societies we can check the following points arranging a tourism activity in a region or taking part in it.

- Are local people involved in the tourism industry as employees?

- Does the organization co-operate with the local businesses?

- Does it have a respectful attitude to local culture?

- Is there respect to nature and how it is protected?

- How much economic benefit will the local population get from tourism?

- Are tour operators concerned about ecological hotels, transport and restaurants?

We can see here that there is a great challenge to make a profitable business running tourism in an area without some negative effects to the local communities. It is possible for tourism industry to co-operate with other industries and bring benefits to both local population and tourism industry.

\section{Conclusion}

Tourism is expected to continue to grow in the future owing to population growth, improved living standards, improvements and expansion of transportation systems, increasing free time and other factors. According to forecasts by the World Tourism Organization, international tourist arrivals are likely to almost triple over the next two decades, with nearly 1.6 billion tourists visiting foreign countries by the year 2020. This will further increase the pressure on the natural, cultural \& socio-economic environments of popular destinations. More intensified efforts to address sustainability in tourism development are required. 


\section{References}

- International Council on Local Environment Initiatives, Commission on Sustainable Development, Seventh Session, 19 - 30, April 1999, New York, 'Tourism and Sustainable Development, Sustainable Tourism,' A Local Authority Perspective.

- Singh Ratandeep, 'Indian Ecotourism'; Environmental Rules and Regulations, Kaniska Publishers, Distributers, New Delhi, 2003.

- Chawla Romila, 'Sustainable Development and Tourism', Sonali Publications, New Delhi, 2003.

- McKercher Bob, 'Sustainable Tourism Development' - Guiding Principles for Planning and Management, presentation to the National Seminar on Sustainable Tourism Development, Bishkek, Kyrgystan, Nov 5-9, 2003.

- Finneli David A and Kavin Ebert, "Tourism and Precautionary Principle", Journal of Sustainable Tourism, Vol. 12, No. 6, 2004, pp $461-479$.

- Farrell A Tracy and Jeffery L Marion, 'The Protected Areas Visitor Impact Management (PAVIM) Framework': A Simplified Process for Making Management Decisions, Journal of Sustainable Tourism, Vol.10, No. 1, 2002, pp $31-51$.

- Page Stephen J., Tourism Management - Managing for Change, Butterworth - Heinemann, An imprint of Elsevier, 2003.

- Hardy A L and J. S Beeton, Sustainable Tourism or Maintainable Tourism: Managing Resources for More Than Average Outcomes, Journal of Sustainable Development, Vol.9, No.3, 2001, pp $168-189$. 